\title{
PROGNOSIS IN IDIOPATHIC THROMBOCYTOPENIC PURPURA OF CHILDHOOD
}

BY

\author{
G. M. KOMROWER and G. H. WATSON \\ From the Royal Manchester Children's Hospital
}

(RECEIVED FOR PUBLICATION JULY 8, 1954)

Many articles have been written about idiopathic thrombocytopenic purpura but few differentiate adequately between children and adults. This is unfortunate, as it is generally agreed that the disease is much milder in children than in adults, and has a better prognosis. We propose, therefore, to discuss a number of cases in children and to review some other series in order to obtain a clearer picture of the course and prognosis of the disease in children.

\section{Criteria for Inclusion}

This series of 43 cases includes all the 40 cases under the age of 15 years seen in three Manchester children's hospitals in the years 1948-53 inclusive. The term 'thrombocytopenic' is used in this study to indicate a platelet count of less than 120,000 per c.mm. determined by direct methods. In all cases except three the platelet count was below 100,000 on more than one occasion. Cases of thrombocytopenia following acute infections have been included, but not those occurring during the course of fulminating infections or other diseases, during the neonatal period, or as a reaction to drugs.

\section{Clinical Findings and Course}

The clinical features were typical; most cases had bruising and petechiae and a few had haemorrhages from one or more sites; one case had mild epistaxis as the only clinical manifestation. The spleen was palpable in only 11 cases and the enlargement was but slight. Clement and Diamond (1953) reported well-marked systolic bruits in $8 \%$ of their cases, but we have been unable to confirm this observation.

Only one relative of 32 of the surviving children had any tendency to bleed or bruise easily; this was the mother of a child with chronic idiopathic thrombocytopenic purpura. Her platelet count, however, was normal.

The age distribution is shown in Fig. 1; there was no difference in distribution between the sexes. The duration and outcome of the disease are shown in Fig. 2.

Most of the cases fall into one of two groups: an 'acute group' of 24 patients, who either died or recovered spontaneously and completely within six months of the onset, and a 'chronic group' who were ill for more than six months. In addition there were seven 'indeterminate' patients who underwent splenectomy within four months of the onset

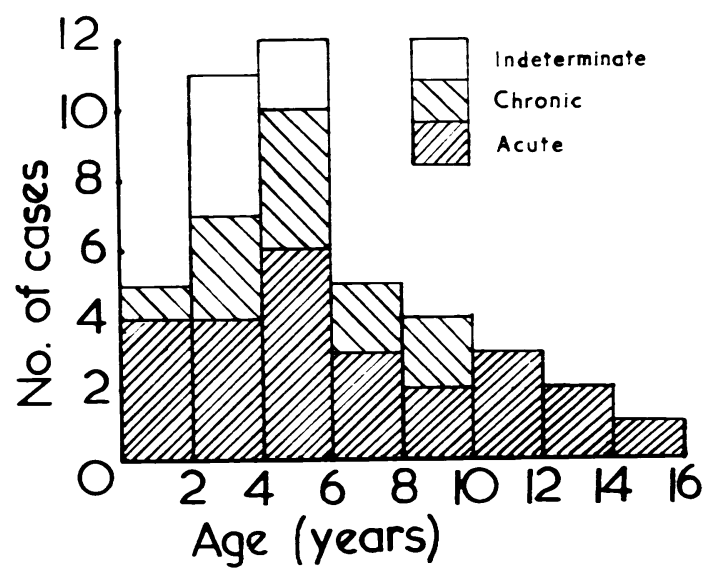

FK. 1.

of symptoms. Three of these indeterminate cases had well-defined onsets, and their symptomsthough not their platelet counts-seemed to be improving at the time of splenectomy; two more were severely ill with a sudden onset, one having had an intracranial haemorrhage. These five patients seem more likely to belong to the 'acute' than to the chronic group, and are referred to as 'probably acute' cases. The other two indeterminate cases could not be allotted to either group. 


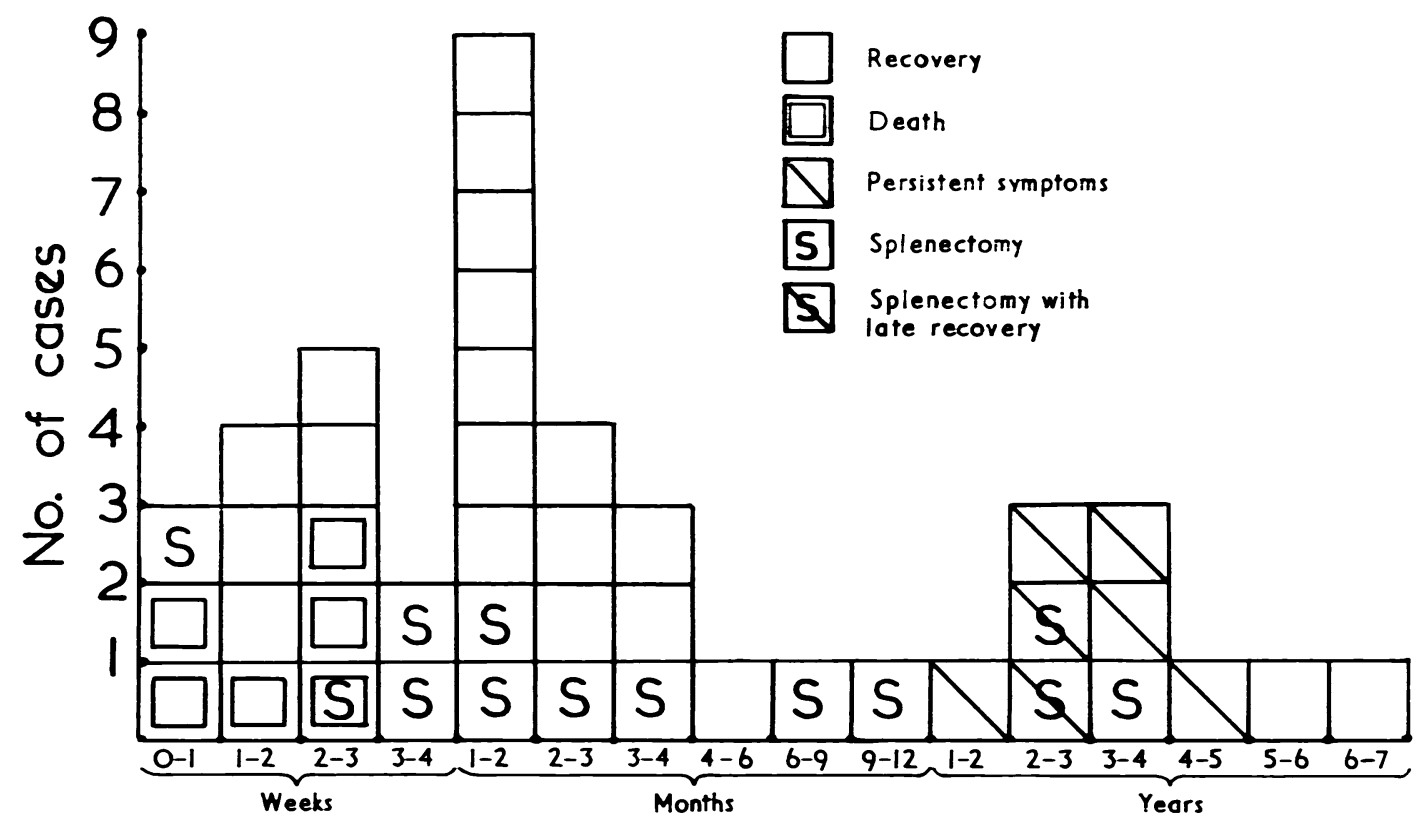

FiG. 2-Duration of thrombocytopenia.

\section{Acute Cases}

Of these 24 children, 12 had mild and 12 severe symptoms, i.e. extensive ecchymoses, severe epistaxis, or spontaneous bleeding of varying severity from other sites. Six of the severe cases died.

All the remaining 18 children made a complete and spontaneous recovery, 11 within six weeks and all but one within three months of the onset of symptoms. In this latter case mild symptoms lasted for six months, after which there was a clinical and haematological remission which has lasted five years.

All cases were followed for over 12 months from the time of remission, 13 for periods of two to five years. There were no relapses once the platelet count had risen above 200,000 per c.mm. except in one case. This boy had apparently recovered completely from acute idiopathic thrombocytopenic purpura within three months; five months later, when his platelet count was 300,000 , some spontaneous bruising appeared over a period of three weeks. He quickly recovered, however, and nine months later remains symptom-free.

Symptoms appeared quite suddenly, and all cases but two were seen within two weeks of their first symptoms. In several cases all clinical manifestations cleared after a few days, and in no case was the severity of the disease in the first month exceeded later.
Six patients in this group did not recover; three died from uncontrollable haemorrhage, and three from intracranial bleeding. One boy had a splenectomy the day before he died; he had had an intracranial haemorrhage shortly before admission in the third week of illness. We may conveniently mention here the only other child in the whole series who had any serious complication, a boy in the 'probably acute' group who had an intracranial haemorrhage in the third week of his illness. Splenectomy later cured the idiopathic thrombocytopenic purpura but he remains blind and hemiplegic. All these children had severe skin and mucosal bleeding before their major haemorrhages, and all the major haemorrhages occurred within three weeks of the onset of symptoms.

Intracranial bleeding in idiopathic thrombocytopenic purpura is commonly fatal, and hence, although one of these children survived, we shall for convenience refer to this group of seven patients as 'fatal cases'.

The platelet count in five of the 17 patients who recovered remained quite low for periods of three to five weeks after symptoms had ceased, but in the other 12 the symptoms continued until the platelet count neared 200,000 . In general there was no correlation between the platelet level and the severity of symptoms, and in some fulminating cases which died within a few days after the first symptoms the 
platelet count did not fall below 90,000. McLean, Kreidel and Caffey (1932) also commented on the high platelet count found in some of their fulminating cases.

\section{Chronic Cases}

Of the 12 patients whose symptoms continued for over six months, nine had symptoms for over two years. Of the other three, one still has symptoms after 12 months, while two were cured by splenectomy after six and a half and 12 months respectively.

The onset of symptoms was usually less sudden than in acute cases. This is illustrated by the fact that nine chronic cases had had symptoms for nine months or more before seeking medical advice. In two girls, however, the illness began suddenly and they were seen a few days later; their progress was at first similar to that of an acute case, but the stage of improvement which began after a few weeks was prolonged for over 12 months in one case and for five years in the other.

The severity of symptoms varied greatly. One little boy had very mild bouts of bruising which began at the age of 2 years, and continued for six years; since then he has been symptom-free for two years. The diagnosis was made only when he attended because of an unrelated condition. His platelet counts were in the range of 100 to 120,000 while bruising occurred, but have been over 250,000 since it ceased. Two patients required transfusion because of severe epistaxis, but no child had any graver bleeding.

The six cases besides the little boy just mentioned who did not undergo splenectomy have all tended to improve, some after a few months and others after some years, during which there was little change in the clinical features. Only one, however, appears to have recovered completely so far. This is one of the girls referred to above who had moderately severe symptoms of sudden onset at the age of 5 years, followed by milder recurrent attacks during the next five years. Her symptoms improved, and ceased at the age of 10 years; at the age of 15 years she remains well, and menstruates normally.

In three cases which, on the whole were improving, the platelet counts during bouts of bruising were between 100,000 and 200,000 per c.mm., but during remissions the platelet count rose to over 200,000 per c.mm. The rule observed in acute cases-that relapse rarely follows a platelet count of over 200,000 - does not apply to chronic cases.

Five chronic cases underwent splenectomy. Only three had an immediate and permanent cure and were well one to four years later. In the fourth case symptoms and thrombocytopenia ceased about two years after operation, and the child remains well three years later, while the fifth has improved steadily during the 15 months since splenectomy.

\section{Indeterminate Cases}

Seven cases underwent splenectomy within four months of the onset of symptoms. All were cured symptomatically and haematologically immediately after operation and are well one to 13 years later, except for the boy who had intracranial bleeding.

\section{Prognosis}

Some features which may help the assessment of prognosis are discussed.

Onset of Symptoms. A history of a well-defined onset was obtained in nearly all acute cases, but in only two out of 12 chronic cases. Of 24 cases with a well-defined onset, only two did not recover or die within six months.

Antecedent Infections. An infective illness preceding the appearance of purpura by three weeks or less was noted in 12 out of 22 acute and "probably acute' cases which recovered, and in four of the seven fatal cases; this history appears to be of little help in determining the possible seriousness of a case. A history of antecedent infection was not obtained in any chronic case; the onset, however, was usually so insidious that it is possible that the relation of a mild infection to the purpura may not? have been appreciated by the parents.

As a generalization one can say that if an infection has occurred during the three weeks preceding the appearance of purpura then the disease has been of sudden onset and, therefore, is likely to run a relatively short course.

Clinical Features. Spontaneous bleeding from more than one site (six cases out of seven) and extensive ecchymoses (seven out of seven) occurred before the final haemorrhage in the fatal cases, and these two signs are of considerable prognostic importance.

Splenomegaly was equally uncommon in acute and chronic cases.

Urticaria occurred in seven of 41 children. It was not correlated in any way with the course of the disease.

Eosinophilia. Schwartz and Kaplan (1950) claimed that a bone marrow eosinophilia of over $5 \%$ indicated a good prognosis, but others (Newton and Zuelzer, 1951) have denied this, or have thought the correlation only slight (Presley, Best and Limarzi, 1952). 
TABLE

\begin{tabular}{|c|c|c|c|c|c|c|c|}
\hline Author & & $\begin{array}{l}\text { No. of Cases } \\
\text { Reported }\end{array}$ & Deaths & Time of Death & $\begin{array}{l}\text { Minimum } \\
\text { No. of Cases } \\
\text { of Duration } \\
\text { Over } 1 \text { Month }\end{array}$ & $\begin{array}{l}\text { Cases of } \\
\text { Duration Over } \\
\text { 1 Month with } \\
\text { Splenectomy }\end{array}$ & $\begin{array}{c}\text { Cases of } \\
\text { Duration Over } \\
1 \text { Month without } \\
\text { Splenectomy }\end{array}$ \\
\hline McLean et al. (1932) .. & . & 21 & 4 & $\begin{array}{l}3 \text { in first mth. } \\
1 \text { at } 13 \mathrm{mth} .\end{array}$ & 5 & 2 & 3 \\
\hline Clement and Diamond (1953) & . & 90 & 2 & $\begin{array}{l}1 \text { fulminating } \\
1 \text { at } 2 \frac{1}{2} \text { r. } \\
\text { (nephritis) }\end{array}$ & 55 & 23 & 32 \\
\hline Newton and Zuelzer (1951) & . & 42 & 3 & 3 fulminating & 13 & 6 & 7 \\
\hline Present .. & . & 43 & 6 & 6 in first $\mathrm{mth}$. & 33 & 9 & 24 \\
\hline Total $\quad \ldots$ & . & 196 & 15 & 13 in first $\mathrm{mth}$. & 106 & 40 & 66 \\
\hline Stroebel et al. (1949) & . & 31 & 0 & & & & \\
\hline Evans and Perry (1943) & . & 25 & 4 & $\begin{array}{l}\text { All presented with } \\
\text { fatal haemorrhages }\end{array}$ & & & \\
\hline Presley et al. (1952) & . & 26 & 0 & & & & \\
\hline Total & . & 278 & 19 & & & & \\
\hline
\end{tabular}

In the present series the bone marrow was examined in 15 cases, and an eosinophilia was found in nine of them. Rather fewer than $50 \%$ of all the cases had an eosinophilia in the peripheral blood. There was no close correlation between blood and marrow eosinophilia, a connexion suggested by Hirsch and Dameshek (1951) but which Schwartz and Kaplan (1950) and Presley et al. denied.

Neither blood nor marrow eosinophilia was in any way correlated with the course of the disease or with the response to splenectomy in survivors, except that six of the seven fatal cases had no peripheral eosinophils. The two children with the highest eosinophilia had splenectomies; one was cured at once, but in the second case the symptoms were only slightly improved.

Phatelet Levels. Platelet levels in the first three weeks have not had any prognostic significance.

\section{Discussion}

We have combined with the figures of the present series those from six of the articles which provide adequate information about the course of the disease in children (McLean et al., 1932; Stroebel, Campbell and Hagedorn, 1949; Clement and Diamond, 1953; Newton and Zuelzer, 1951; Evans and Perry, 1943; Presley et al., 1952). This gives a total of 278 cases of idiopathic thrombocytopenic purpura in children, of whom 19 died (Table). One died after persistent and severe bleeding had continued for 13 months despite splenectomy, another from chronic nephritis; the remaining 17 children all died within one month of the onset of symptoms.
It is not possible to deduce exactly the duration of illness in all these children but, of 196 cases in these series where detailed information is given, at least 106 cases had symptoms for over a month. In the 196 cases there were 15 deaths, 13 in the first month of illness.

Of these 106 cases, 40 underwent splenectomy; 66 cases, therefore, had symptoms which lasted for more than a month (48 of them for over six months) but did not undergo splenectomy. None of them died from idiopathic thrombocytopenic purpura.

The important points are the facts that nearly all the deaths occurred in the first month of the disease, and that no fatal haemorrhages occurred suddenly in patients who had had symptoms for over six months and fall into our chronic group.

We conclude from these observations that in cases seen in the first month of illness the risk of serious complications is appreciable, but that patients who survive this period will, more often than not, undergo complete remission in six months or less, and run much slighter risk of severe complications.

The risk of splenectomy in the acute stages is great (Wintrobe, 1951) and we suggest that all seen in the first month of illness, especially those who have spontaneous haemorrhages, should be given treatment including A.C.T.H. or cortisone in adequate doses (Dameshek, 1952); $50 \%$ of cases will undergo remission on such regimes (Limarzi and Best, 1953) and even if remission is incomplete the danger of serious bleeding may be avoided.

In the period one to six months after onset, an expectant policy can be safely adopted, and splenectomy is not indicated, except in the occasional patient whose symptoms are worsening and a 
chronic course seems likely. Splenectomy should certainly be avoided if symptoms are clearing even if platelets remain low in number. After six months splenectomy should be considered, and the decision to operate should depend on the degree of disability produced. The operation should not be carried out merely through fear of sudden disastrous haemorrhage, as the risk of such bleeding is remote and probably of the same order as the risk of splenectomy.

\section{Summary}

The mortality from acute idiopathic thrombocytopenic purpura is appreciable: in the more severe cases (extensive bruising and bleeding other than mild epistaxis) immediate treatment is indicated. Cases of acute onset which survive the first month nearly all recover spontaneously within six months, the majority within three months.

The mortality from chronic idiopathic thrombocytopenic purpura is very small; in such cases splenectomy should be considered only with regard to the degree of disability produced by the symptoms and not because of a very slight chance of the sudden occurrence of grave haemorrhage.

The best guide to the length of course which a case of idiopathic thrombocytopenic purpura is likely to run is the mode of appearance of symptoms and the presence or absence of a history of antecedent infection.
The haematological findings we have discussed have been of little prognostic value.

We are indebted to Dr. H. B. Marsden (pathologist, Royal Manchester Children's Hospital) for reviewing the marrow films, and to all the physicians who allowed us access to their case notes.

In addition, we wish to thank Dr. M. C. G. Israels for his advice and his help in reading the script.

\section{RefERENCES}

Clement, D. H. and Diamond, L. K. (1953). Amer. J. Dis. Child. 85,259 .

Dameshek, W. (1952). Brit. med. J., 2, 612

Evans, H. and Perry, K. M. A. (1943). Lancet, 2, 410

Hirsch, E. O. and Dameshek, W. (1951). Arch. intern. Med., 88, 701 Limarzi, L. R. and Best, W. R. (1953). J. Lab. clin. Med., 42, 919.

Mclean, S., Kreidel, K. and Caffey, J. (1932). J. Amer. med. Ass. $98,387$.

Newton, W. A. and Zuelzer, W. W. (1951). New Engl. J. Med. 245, 879.

Presley, S. J., Best, W. R. and Limarzi, L. R. (1952). J. Lab. clin. Med., 40, 503

Schwartz, S. O. and Kaplan, S. R. (1950). Amer. J. med. Sci. 219. 528.

Stroebel, C. F., Campbell, D. C. and Hazedorn, A. B. (1949). Med. Clin. N. Amer. 33, 1027

Wintrobe, M. M. (1951). Clinical Hematology, 3rd ed., p. 503. Philadelphia.

\section{Addendum}

Since the above paper was presented for publication we have read an article entitled 'Splenectomy for Idiopathic Thrombocytopenic Purpura ' (Simpkiss and Cathie, 1954), which covers many of the points discussed above and contains severaf similar conclusions.

- Simpkiss, M. J. and Cathie, I. A. B. (1954). Gt. Ormond St. J., 7, 9: 